\title{
Magnitude and Associated Factors of Postoperative Myalgia Among Patients Who Undergo Surgery in Wolaita Sodo Teaching and Referral Hospital, Southern Ethiopia
}

\author{
Bulcha Guye Adema ${ }^{1, ~ *, ~ M o h a m m e d ~ S u l i e m a n ~ O b s a ~}{ }^{2}$, Mihret Zerifu ${ }^{2}$, Dirba Bekele ${ }^{2}$, Desta Yacob ${ }^{2}$ \\ ${ }^{1}$ Department Pediatrics and Neonatal Nursing, College of Health Science, Woliata Sodo University, Woliata, Ethiopia \\ ${ }^{2}$ Department Anesthesia, College of Health Science, Woliata Sodo University, Woliata, Ethiopia
}

Email address:

bulchaguye@gmail.com (B. G. Adema)

*Corresponding author

To cite this article:

Bulcha Guye Adema, Mohammed Sulieman Obsa, Mihret Zerifu, Dirba Bekele, Desta Yacob. Magnitude and Associated Factors of Postoperative Myalgia Among Patients Who Undergo Surgery in Wolaita Sodo Teaching and Referral Hospital, Southern Ethiopia. International Journal of Biomedical Science and Engineering. Vol. 8, No. 1, 2020, pp. 1-5. doi: 10.11648/j.ijbse.20200801.11

Received: February 29, 2020; Accepted: March 18, 2020; Published: April 14, 2020

\begin{abstract}
Introduction: Even though, Suxamethonium is the only short acting and accepted standard for rapid sequence intubation, it is associated with a high risk of complications. Some complications are minor, but others are potentially life threatening. Post-operative myalgia and fasciculation are the two most common and distressing side effects of succinylcholine administration. Objective: To assess the magnitude and associated factors of postoperative myalgia following Suxamethonium administration among patients undergoing surgery in Wolaita Sodo Teaching and Referral Hospital from April 30- May 30, 2019. Methods: Facility based cross sectional survey will be conducted by using convenient sampling technique. Training was given for data collectors and supervisors. Regular supervision and follow up were made. Data was entered in to Epi info version 7 software and transported to SPSS version 20 for analysis. Odd ratio and $95 \%$ confidence interval was computed. Bivariate and Multivariate analysis used to identify factors associated with hypotension. Results: The magnitude of postoperative myalgia is high at 12 hour in which 18 (36\%) develop mild pain where us the magnitude is lower at 24 hour, $14(28 \%)$. More than half $27(54 \%)$ have no postoperative myalgia at 12 hour. Patients who did not take pretreatment agent before administration of Suxamethonium were 15 times more likely to develop post-operative myalgia at 12 hour when compared to patients who take pretreatment agent before Suxamethonium administration (AOR=15.12, 95\%CI: 1.39, 163.53) Conclusion: The magnitude of Suxamethonium induced myalgia is higher at 12 hour than 24 hour post operative and lack of per-treatment agent and repeated dose of Suxamethonium are main risk factors of postoperative myalgia.
\end{abstract}

Keywords: Suxamethonium, Postoperative Myalgia, Magnitude

\section{Introduction}

Suxamethonium induced myalgia is a muscle pain that occurs after administration of Suxamethonium [1]. The incidence of muscle pain after administration of succinylcholine varies from $0.2 \%$ to $89 \%$ and it occurs frequently after minor surgery, especially in women and in Ambulatory rather than bed ridden patients [2]. It is a frequently used blocking agent to facilitate endotracheal intubation during general anesthesia.

Suxamethonium is usually preferred due to its rapid onset and short duration of action [3]. However, the effectiveness of this drug is limited by certain adverse effects [4]. some complications are minor, but others are potentially life threatening. Post-operative myalgia and fasciculation are the two most common and distressing side effects of succinylcholine administration [5].

Post-operative myalgia after administration Suxamethonium has been recognized for many years, but the exact mechanism in which it causes the muscle pain is not fully understood, Most believe that it is due to uncoordinated contraction of muscle that occurs a few seconds before the 
muscle relaxation. Suxamethonium has Side effects such as bronchospasm, tachycardia, fall in blood pressure and after the patient has been up and walking around for about eight hours, aches and pains start, lasting two or three days; in some cases they are severe and may last for as long as six days [6].

Suxamethonium a rapid onset neuromuscular blocking agent with short duration of action but it causes postoperative myalgia and/or muscle damage with adverse biochemical harmful effects of increased levels of serum potassium, myoglobin and creatine kinase (CK), malignant hyperthermia, raised intraocular pressure and intracranial pressure and Various reasons, including involvement of free radicals, and alphatocopheral, have been suggested to cause these changes $[7,8]$. Before succinylcholine administration, pretreatment agents like lidocaine is administered, which is proven to be the useful for the reduction of postoperative myalgia [9].

Postoperative myalgia is one of the major factors that lead to the patient for prolongs stays post operatively in the bed. It is a disturbing condition in surgical patients accompanied by strong psychological and emotional components and restricts the patient from post-operative discharge $[2,4,7]$.

Several methods have been used to prevent or reduce the incidence of succinylcholine-induced muscle fasciculation and myalgia including pretreatment with lidocaine, diazepamor diphenylhydantion, and sub paralyzing doses of non-depolarizing muscle relaxants or succinylcholine [9-11].

Therefore the aim of this study is to assess the magnitude and associated factors of postoperative myalgia following Suxamethonium administration among patients undergoing surgery in Wolaita Sodo teaching and referral hospital.

\section{Method and Materials}

\subsection{Study Setting}

Institutional based cross sectional study design was conducted at Wolaita Soddo University teaching and referral Hospital.

\subsection{Source Participants}

All Surgical patients who underwent surgery with general anesthesia at Wolaita Sodo Teaching and Referral Hospital were source population where as all randomly selected surgical patients who underwent surgery with general anesthesia in Wolaita Sodo Teaching and Referral Hospital from April 30- May 30, 2019. Patients with preexisting muscle disease and patients or patient's families who refused to give consent were excluded.

\subsection{Sampling Technique and Sample Size Determination}

With the Assumption of patient flow by itself is random, and in order to gate adequate sample size we use convenience sampling technique. All surgical patients undergoing surgery with Suxamethonium administration will be surveyed, because we are unable to get adequate sample size within this study period if we make it probability sampling technique and if we make it retrospective chart review important independent variables will be missed due to lack of recording.

\subsection{Data Collection Tools and Procedure}

Data was collected using pretested structured questionnaires. It was prepared in English and translated to Amharic and again back translation to English was made to check for consistency. Data was collected by two BSC holder anesthetists and supervised by one MSC holder Anesthetist.

\subsection{Data Quality Assurance}

Data collectors and supervisors were trained for a half day on each items included in the study tools, objective, relevant of study, right of respondents, confidentiality of information obtained. During data collection, regular supervision and follow up was made. Investigator was check for completeness and consistency of data on daily basis. Once the data was collected and checked for completeness, consistency and accuracy, it was sorted, categorized and summarized. Double entry was made on $10 \%$ of the collected population. Data Analyzing and processing.

The data was entered on epi info version 7 and was exported to SPSS version 20 computer program for analysis. Descriptive statistics was used to summarize data, tables and figures for display results. Bivariate and multivariate analysis was used to see the effect of independent variable on post spinal hypotension. Variables which were significant on bivariate analysis at p- value less than 0.2 was taken to multivariate analysis. In multivariate analysis P-value of less than 0.05 was used as a cut of point for presence of association. Strength of association was measured by $95 \%$ confidence interval and/ Odd ratio.

\subsection{Ethical Consideration}

Ethical clearance and approval was obtained from ethical review committee, Anesthesia department, Wolaita Soddo University. Permission to conduct was obtained from Gandhi memorial Hospital. Informed written consent was secured from every study participant before the start of the interview after telling them about the objective of the study. The obtained data was only used for study purpose. Confidentiality and anonymity were ensured.

\subsection{Operational Definition}

Succinylcholine induced myalgia: - is a muscle pain due to administration of succinylcholine which results from hormonal release like prostaglandins and also due to fasciculation. It's often detected by asking the site of pain which usually locates on upper abdominal muscle, neck, shoulder and body aches presents in such cases.

Postoperative myalgia: -muscle pain experienced after operation, either due to succinylcholine administration or other risk factors which cause muscle pain i.e. diabetes mellitus, old age inflammatory diseases, female gender and 
obesity etc.

Nil: - No muscle pain or stiffness

Mild myalgia: -muscle pain or muscle stiffness at one site but not causing disability or limiting activities.

Moderate myalgia: -muscle pain or muscle stiffness at one or more site but not causing disability or limiting activities.

Severe myalgia: -muscle pain or stiffness at one or more site and causing disabilities or limiting Activity, causing inability to cough without distress and requiring analgesic therapy.

Pretreatment: -administration of any drugs that will use for different purpose intraoperatively.

Repeated dose: -administration of a given drug more than ones.

\section{Result}

Socio demographic characteristics

From the total respondents majority $15(30 \%)$ are in the age group of 25 to 35 age and majority of them 27 (54\%) are males in sex. Most of the respondents $32(64 \%)$ are wolaita in Ethnicity and more than half 29 (58\%) are Protestant religion followers and almost more than half of the respondents $28(56 \%)$ are from rural residents. And majority of the respondents $19(38 \%)$ were unable to read and write and most of the respondents $16(32 \%)$ occupational status were house wife (Table 1).

Table 1. Social-demographic characteristics of patients undergoing surgery in WolaitaSodo Teaching and Referral Hospital, 2019 [N=50].

\begin{tabular}{|c|c|c|c|}
\hline Variables & Categories & Frequency & Percentage (\%) \\
\hline \multirow{5}{*}{ Age of participant } & $18-25$ & 7 & 14 \\
\hline & $25-35$ & 15 & 30 \\
\hline & $35-45$ & 12 & 24 \\
\hline & $45-55$ & 8 & 16 \\
\hline & above 55 & 8 & 16 \\
\hline \multirow{2}{*}{ Sex of participant } & Male & 27 & 54 \\
\hline & Female & 23 & 46 \\
\hline \multirow{2}{*}{ Residence } & Urban & 22 & 44 \\
\hline & Rural & 28 & 56 \\
\hline \multirow{4}{*}{ Educational status } & Unable to read and write & 19 & 38 \\
\hline & Primary school & 17 & 34 \\
\hline & Secondary school & 9 & 18 \\
\hline & Diploma and above & 5 & 10 \\
\hline \multirow{5}{*}{ Occupation } & House wife & 16 & 32 \\
\hline & Government employ & 2 & 4 \\
\hline & Private business & 12 & 24 \\
\hline & Student & 8 & 16 \\
\hline & Farmer & 12 & 24 \\
\hline
\end{tabular}

Magnitude of Postoperative myalgia

The magnitude of postoperative myalgia is $23(46 \%)$ at 12 hour. Out of the total respondents more than half $27(54 \%)$ have no postoperative myalgia at 12 hour and only $2(4 \%)$ develop sever pain following suxamethonium administration at 12 hour. Majority of the respondents $33(66 \%)$ have no postoperative myalgia at 24 hour and $14(28 \%)$ have mild pain at 24 hour postoperatively (Figure 1).

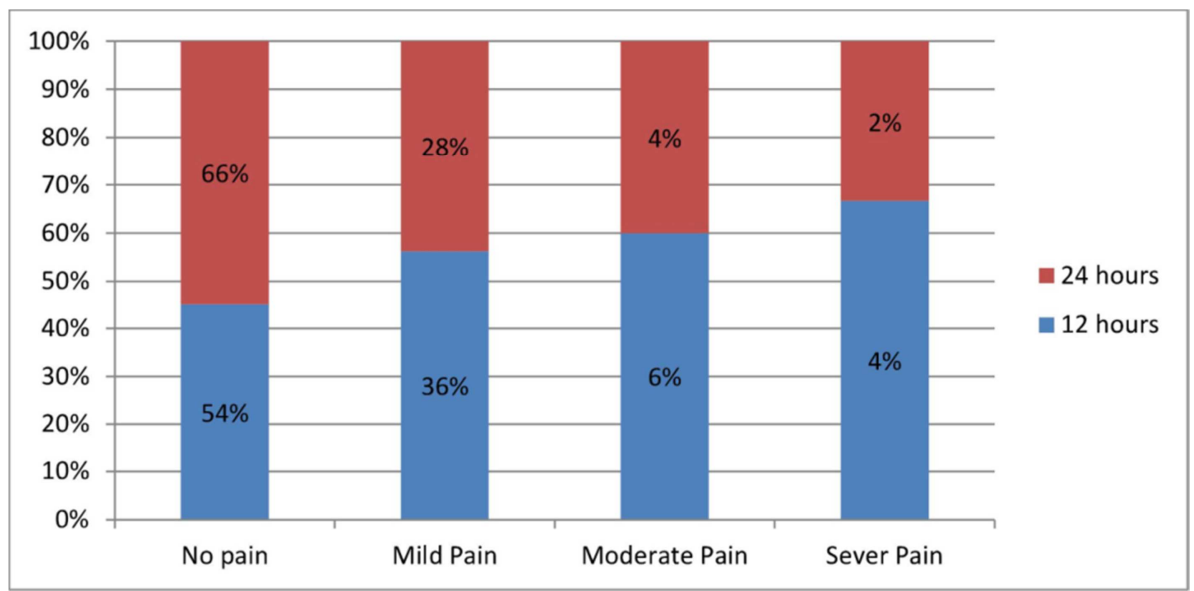

Figure 1. Severity of postoperative myalgia at 12 and 24 hour following suxamethonium administration among patients undergoing surgery in Wolaita Sodo Teaching and Referral Hospital, 2019 [N=50].

Associated factors of Postoperative myalgia following suxamethonium administration.

In bivariate logistic regression analysis factors which were significantly associated with postoperative myalgia were Educational status, occupation, type of surgery, dose of suxamethonium and take pretreatment agent. Variables which revealed as significant on bivariate analysis with $\mathrm{p}$-value less than 0.2 were introduced into multiple logistic regression.

In multiple logistic regressions analysis factors that were significantly associated with postoperative myalgia were dose 
of suxamethonium and take pretreatment agent. Patients who under gone surgery with repeated dose of suxamethonium were 16 times more likely to develop post-operative myalgia at 12 hour when compared to single dose of suxamethonium (AOR=16.3, 95\%CI: 1.02, 25.92). Patients who did not take pretreatment agent before administration of suxamethonium were 15 times more likely to develop post-operative myalgia at 12 hour when compared to who take pretreatment agent before suxamethonium administration $(\mathrm{AOR}=15.12$, 95\%CI: 1.39 , 163.53) (Table 2).

Table 2. Multivariate logistic regression analysis on associated factors of Postoperative myalgia following Suxamethonium administration among patients undergoing surgery in WolaitaSodo Teaching and Referral Hospital, 2019 [N=50].

\begin{tabular}{|c|c|c|c|}
\hline Variables & COR $(95 \%$ CI) & AOR (95\%CI) & $P$-value \\
\hline \multicolumn{4}{|l|}{ Type of surgery } \\
\hline Elective & 1.0 & 1.0 & \multirow{3}{*}{0.51} \\
\hline Emergency & $0.38(0.11,0.85)$ & $0.52(0.072,3.76)$ & \\
\hline \multicolumn{3}{|c|}{ Dose of Suxamethonium } & \\
\hline Single dose & 1.0 & 1.0 & \multirow{3}{*}{$0.048^{*}$} \\
\hline Repeated dose & $2.25(1.65,7.7)$ & $16.28(1.02,25.92)$ & \\
\hline \multicolumn{3}{|c|}{ Patient take pretreatment agent } & \\
\hline No & $3.5(1.06,11.7)$ & $15.12(1.39,163.5)$ & $0.025^{*}$ \\
\hline
\end{tabular}

*significant at $\mathrm{p}$ - value less than 0.05 .

\section{Discussion}

In this study the magnitude of postoperative myalgia is 23 (46\%) at 12 hour, which is lower than a study conducted in India which was 57.5\% [12]. And higher than a study conducted in England which showed that the overall incidence of POM (post-operativemyalgia) was $22.1 \%$ [3]. It is lower than a study conducted in Iran referral Hospital in which the incidences of myalgia was $52.4 \%$ in placebo group but higher than in pretreated with diclofenac which were $23.8 \%$ [13]. This variation might be due to the difference in muscular fitness and pretreatment agents.

This study revealed that magnitude of postoperative myalgia is [12] (34\%) at 24 hour which is similar with a study conducted in India in which $30 \%$ patient of normal saline group had myalgia and it is also consistent with another study which revealed the incidence of muscle pains was $35 \%$ in the groups given Suxamethonium immediately [14] but it is higher than a randomized control trial study conducted in USA which revealed that the incidence of postoperative myalgia was $28 \%$ with pretreatment of lidocaine. It is lower than other study, a meta-analysis of randomized trial showed that the incidence of myalgia at $24 \mathrm{~h}$ was $50 \%$ [5] and other study conducted in Iran referral Hospital in which the incidences of myalgia was $47.6 \%$ in placebo group but higher than in pretreated with diclofenac which was (19.1\%) [13].

The magnitude of Suxamethoneum induced post-operative myalgia in the first $24-48 \mathrm{hrs}$ was higher. To minimize the magnitude of Suxamethoneum induced post-operative myalgia and post-operative patient discomfort differen prevention techniques should be applied. If possible it better to avoid the use of Suxamethoneum regularly for elective surgical patients [15]. Suxamethoneum has been widely used as a short acting muscle relaxant in both clinical surgery and electric convulsion therapy [16].

The possible reason for this variation might be due to the difference in pretreatment agents and dose of
Suxamethonium.

\section{Conclusion}

In this study there is high magnitude of postoperative myalgia is high and use of pretreatment agent reduces postoperative myalgia.

\section{Abbreviations}

SUX=Suxammethonium, POM=post-operative myalgia, $\mathrm{Mg} / \mathrm{Kg}=$ Milligram per body weight in kilogram

\section{Declarations}

\section{Availability of Data and Material}

All data are already described and included in the manuscript.

\section{Competing Interest}

The authors declare that they have no competing interest.

\section{Funding Agency}

This work has been funded by Wolaita Sodo University for data collection. Academic and Research Directorate Office of College of Health Sciences, Wolaita Sodo University, was involved in the project through monitoring and evaluation of the work. The funder had no role in study design, data collection and analysis, interpretation of the data, the decision to publish, or preparation of the manuscript.

\section{Authors' Contribution}

BGA wrote the proposal, participated in data collection, analyzed the data and wrote the manuscript. MSO and MZ contributed in data analysis and revising the drafted manuscript. All the authors read, revised and approved the manuscript before they have given the final approval for publication. 


\section{Acknowledgements}

First of all we would like to express our deepest appreciation goes to wolaita sodo university ICT office for their help in searching different literatures for the development of the proposal.

And finally we would like to thank, wolaita Sodo University, department of anesthesia for giving this chance.

\section{References}

[1] Oxorn DC, Whatley GS, Knox JWD, Hooper J. The importance of activity and pretreatment in the prevention of sexuamethonium myalgias. Br J Anaesth [Internet]. 1992; 69 (2): 200-1. Available from: http://dx.doi.org/10.1093/bja/69.2.200.

[2] Miller RD, Ward TA, Shiboski SC, Cohen NH. A comparison of three methods of hemoglobin monitoring in patients undergoing spine surgery. Anesth Analg. 2011; 112 (4): 85863.

[3] Shafy SZ, Hakim M, Krishna SG, Tobias JD. SuccinylcholineInduced Postoperative Myalgia: Etiology and Prevention. J Med Cases. 2018; 9 (8): 264-6.

[4] Khan MA, Siddiqi KJ, Anjum KM, Hamza A. A randomized controlled study on prevention of succinylcholine induced fasciculation and myalgia by pretreatment with pregabalin in patients undergoing laparoscopic cholecystectomy. Anaesthesia, Pain Intensive Care. 2017; 21 (4): 447-52.

[5] Schreiber JU, Mencke T, Biedler A, Fürst O, Kleinschmidt S, Buchinger $\mathrm{H}$, et al. Postoperative myalgia after succinylcholine: No evidence for an inflammatory origin. Anesth Analg. 2003; 96 (6): 1640-4.

[6] Ruddell JS. Suxamethonium Chloride and Muscle Pain. Br Med J. 1957; 2 (5043): 527.

[7] Wong SF, Chung F. Succinylcholine-associated postoperative myalgia. Anaesthesia. 2000; 55 (2): 144-52.

[8] Maddineni VR, Mirakhur RK, Building WM. Volume 48, page 626-628 Myalgia and biochemical changes following suxarnethonium after induction of anaesthesia with thiopentone or propofol V. R. Maddineni, MD, FFARCSI, R. K. Mirakhur, MD, FRCA, A. 1993; 48: 626-8.

[9] Amornyotin S. Can lidocaine reduce suxamethonium induced postoperative myalgia? Vol. 85, Journal of Medical Association of Thailand. 2002. p. S 969-974.

[10] Fatemeh H, Mojgan R. Comparison of atracurium and "minidose" succinylcholine for preventing succinylcholine-induced muscle fasciculations: A randomized, double-blind, placebocontrolled study. Acta Anaesthesiol Taiwanica [Internet]. 2010; 48 (1): 28-32. Available from: http://dx.doi.org/10.1016/S1875-4597(10)60006-9.

[11] Srivastava VK, Agrawal S, Nimbhorkar VK, Mishra A, Sharma S, Panda PK. Prophylactic use of pregabalin for prevention of succinylcholine-induced fasciculation and myalgia: a randomized, double-blinded, placebo-controlled study. Brazilian J Anesthesiol (English Ed [Internet]. 2016; 66 (2): 165-70. Available from: http://dx.doi.org/10.1016/j.bjane.2014.08.004.

[12] Parmar S, Vyas A, Sheikh A. Usefulness of propofol to prevent succinylcholine induced fasciculations and myalgia, a comparison with thiopentone sodium as an induction agent. Int J Med Sci Public Heal. 2013; 2 (2): 339.

[13] Abraham V, Kumar AR, Afzal L. Evaluation of Post Succinylcholine Myalgia and Intubation Conditions with Rocuronium Pretreatment: A Comparison with Vecuronium. Indian J Anaesth. 2008; 52 (5): 551-5.

[14] Nasseri K, Arvien S. Effects of low-dose ketamine on succinylcholine-induced postoperative myalgia in outpatient surgeries: A randomized, double-blind study. J Pain Res. 2016; 9: 503-8.

[15] Newnam PTF, Loudon JM. Muscle pain following administration of suxamethonium: The aetiological role of muscular fitness. Br J Anaesth. 1966; 38 (7): 533-40.

[16] Chloride S, Pains M. Suxamethonium (succinylcholine) chloride. $1954 ; 1$. 